\title{
Self-reported long-term effects of diving and decompression illness in recreational SCUBA divers
}

\author{
Dan McQueen BMed Sci, Gerry Kent PhD and Andrew Murrison MB ChB \\ Department of Psychiatry, University of Sheffield, Sheffield, UK
}

\begin{abstract}
The aim of this study was to examine the long-term effects of neurological decompression illness (NDCI) on recreational divers. Thirty-seven divers who had been treated for neurological decompression illness at least 2 years previously, and a control group of $\mathbf{5 0}$ divers with no history of decompression illness, reponded to a postal questionnaire. Divers in the accident group reported more symptoms of neurological damage, were more likely to believe that diving had a deleterious effect on their health and were more likely to indicate symptoms of psychiatric morbidity. The quantity of diving in the year preceding the survey was associated with reports of neurological damage in both groups and with symptoms of psychiatric morbidity in the accident group. Although requiring confirmation from a longitudinal study, these results suggest that recreational diving can have negative longterm consequences for health, particularly after decompression illness.
\end{abstract}

Keywords: Diving, decompression illness, quality of life

There has been considerable interest in the relationship between decompression illness (DCI) and long-term neurological damage since Rozsahegyi's ${ }^{1}$ report on the health of caisson workers. Existing research into the health effects of compressed-air diving, based largely on commercial diving, has suggested that hyperbaric exposure with or without reported episodes of DCI may cause neuroanatomical deficits $^{2-9}$.

The effects of such damage on intellectual ability and social functioning are less clear. In this context it is useful to use the World Health Organisation' $\mathbf{s}^{10}$ distinction between impairment (the anatomical or physiological abnormality), disability (the way in which the impairment affects everyday activities) and handicap (the effects on roles and responsibilities). Although exposure to compressed gas for prolonged periods and DCI may result in an impairment, there may or may not be a disability or handicap which is noticeable to the individual.

Address for correspondence: Dr G. Kent, Department of Psychiatry, 16 Claremont Crescent, Sheffield S10 2TA, UK

(C) 1994 Butterworth-Heinemann Ltd

0306-3674/94/020101-04
On a number of grounds, Edmonds and Hayward $^{11}$ challenged the contention that repeated compressed air diving and decompression sickness may cause permanent disability. They identify several methodological flaws in the existing research, especially the lack of appropriate comparison groups, inappropriate comparison group selection, and lack of standardized psychometric testing. They conclude that a link between compressed-gas diving and neurological damage is yet to be established.

A further question concerns the vulnerability of individuals. Some sports divers appear to sustain decompression sickness as a result of dives lasting less than one-half the allowable time according to accepted decompression schedules ${ }^{12}$. Others may embark upon highly provocative dive profiles and yet remain unscathed. This variation in response may be due to undefined somatic or environmental factors, or to some combination of the two. Research has generally been limited to comparisons between divers who have been exposed to extensive or minimal compressed air diving, or between divers who have or have not suffered decompression sickness. However, Todnem et al. ${ }^{9}$ suggest that an episode of decompression illness makes the subsequent development of neurological symptoms and signs more likely in individuals who continue to dive.

The aim of the present study was to examine further the effects of NDCI and quantity of diving on self-report measures of health symptoms and psychological distress. If Todnem et al. ${ }^{9}$ were correct, then it would be predicted that continued diving after DCI would be more likely to result in symptoms of ill health and psychological distress than would DCI or repeated diving alone.

\section{Subjects and method}

All subjects in this study were male members of the British Sub-Acqua Club (BSAC). The accident group was selected from the case files held at the Institute of Naval Medicine, Alverstoke, UK. These files relate to those divers treated for NDCI at Alverstoke or treated at decompression facilities elsewhere with the Institute's physicians providing medical advice by telephone. All 87 BSAC cases treated between 1984 and 1988 were included in the study. The comparison group consisted of 120 randomly selected members of BSAC who did not have histories of NDCI. 


\section{Procedure}

All subjects were sent questionnaires and a stamped return envelope through the post in the autumn of 1990. Each questionnaire included sections for demographic information, diving history and practices and the 28-item version of the General Health Questionnaire $(\mathrm{GHQ})^{13}$ as a screen for psychiatric morbidity. Subjects were also asked to indicate if they were currently experiencing any health related symptoms on a check-list based on the consequences of decompression sickness reported in the literature. A free response section on how diving had affected their health was also included.

\section{Results}

\section{Response rates}

Of the 87 questionnaires posted to the accident group, $64(74 \%)$ were returned. Eighteen were returned unopened owing to a change of address. Of the remainder, seven were not included in the analysis because they were not members of BSAC or were diving commercially, and a further two claimed not to have suffered DCI, leaving a sample of 37 completed questionnaires from the accident group. Of the 120 questionnaires sent to the control group, $51(43 \%)$ were returned. One was not included since the respondent was female, leaving a sample of 50 .

\section{Demographic information}

No differences in height, weight, school leaving age, marital status, social class, employment status or smoking or drinking habits were found between the accident and control groups. The accident group was younger (36 versus 44 years; Mann-Whitney $U$ test, $P<0.002)$. There were no differences in the total number of reported dives or the total number of dives over $30 \mathrm{~m}$. Divers in the two groups were equally likely to report that they had disregarded diving recommendations in the past.

Neither $56 \%$ of the accident group nor $13 \%$ of the control group had dived during the previous 12 months. Those in the accident group had made an average of 18 dives in the previous year, compared with 26 for those in the comparison group (MannWhitney $U$ test, $P<0.001)$. These results indicate that the divers in the two groups were similar on most measures, but that those in the accident group were younger, less likely to be diving at the time of the survey and to have made fewer dives in the previous 12 months.

\section{Health data}

The self-reported effects of diving on health were assessed in two ways: the symptom check-list and the free response item. Table 1 illustrates the percentage of divers in the two groups who responded affirmatively to the questions about specific health problems. It indicates that divers from the accident group were
Table 1. Percentage of divers in the two groups reporting specific health symptoms

\begin{tabular}{lccc}
\hline Symptom & $\begin{array}{c}\text { Accident } \\
\text { group }\end{array}$ & $\begin{array}{c}\text { Control } \\
\text { group }\end{array}$ & Significance* \\
\hline $\begin{array}{l}\text { Eyesight } \\
\text { deterioration }\end{array}$ & 40 & 50 & n.s. \\
$\begin{array}{l}\text { Double vision } \\
\text { Hearing }\end{array}$ & 5 & 6 & n.s. \\
$\quad$ deterioration & 32 & 20 & n.s. \\
$\begin{array}{l}\text { Tinnitus } \\
\text { Vertigo }\end{array}$ & 30 & 16 & n.s. \\
$\begin{array}{l}\text { Headache } \\
\text { Epilepsy }\end{array}$ & 19 & 6 & n.s. \\
$\begin{array}{l}\text { Weakness or } \\
\text { clumsiness }\end{array}$ & 46 & 28 & n.s. \\
$\begin{array}{l}\text { Sensitivity to } \\
\text { alcohol }\end{array}$ & 0 & 0 & n.s. \\
$\begin{array}{l}\text { Irritability } \\
\text { Difficulty }\end{array} \quad 19$ & 0 & $<0.01$ \\
$\quad$ concentrating & 27 & 24 & n.s. \\
$\begin{array}{l}\text { Poor appetite } \\
\text { Hot or cold }\end{array}$ & 14 & 6 & n.s. \\
$\quad$ feelings & 46 & 26 & n.s. \\
\hline
\end{tabular}

*Mann-Whitney $U$ test; n.s. not significant

more likely to report symptoms on nine of the 13 items but significant differences were found on only two measures: 'weakness or clumsiness' and 'hot or cold feelings for no reason'.

The results of the free response item on the perceived impact of diving on health were subjected to a content analysis. The categories, which ranged from 'positive effect' to 'significant handicap' are shown in Table 2.

An independent judge, blind to the original categorization, achieved $88 \%$ agreement with our categories. Significantly more of the accident group reported that diving had an adverse effect on health (Mann-Whitney $U$ test, $P<0.01$ ). Forty-three percent of the accident group but only $10 \%$ of the control group believed that diving was responsible for any impairment, disability or handicap.

Table 2. Numbers of divers in the two groups reporting positive or negative effects of diving

\begin{tabular}{lcr}
\hline Response & $\begin{array}{c}\text { Accident } \\
\text { group }\end{array}$ & $\begin{array}{c}\text { Control } \\
\text { group }\end{array}$ \\
\hline $\begin{array}{l}\text { Positive effect: diving has led to improved } \\
\text { health, improved fitness, reduced stress } \\
\text { or relaxation. }\end{array}$ & 6 & 12 \\
$\begin{array}{l}\text { No effect. } \\
\text { Mild negative effect, impairment without } \\
\text { disability: small areas of cutaneous } \\
\text { sensory abnormality. }\end{array}$ & 5 & 0 \\
$\begin{array}{l}\text { Moderate negative effect, some disability: } \\
\text { difficulty concentrating, poorer memory } \\
\text { or personality change. Some deafness, } \\
\text { nystagmus, reduced bladder control. }\end{array}$ & 8 & 5 \\
$\begin{array}{l}\text { Severe negative effect with handicap: } \\
\text { reduced muscular control, impaired gait } \\
\text { or sensory changes which interfere with } \\
\text { normal activities. }\end{array}$ & 3 & 0 \\
\hline
\end{tabular}




\section{Psychological well-being}

The binary scoring method was used to score the GHQ. A greater number of the accident group (19\%) than the control group $(4 \%)$ scored above the cut-off for the presence of psychiatric difficulties (Fisher exact probability test, $P<0.05$, one-tailed). No significant difference was found between the diving and control groups on the somatic, anxiety and social functioning subscales, but the accident group scored higher on the severe depression scale (means $=0.28$ versus 0.02; Mann-Whitney $U$ test, $P<0.05$ ). These results indicate that the accident group divers were more likely to be suffering from a psychiatric difficulty, mainly due to symptoms of depression.

\section{Regression analysis}

The above results indicate that NDCI is associated with some psychological and health difficulties. Divers in the accident group were younger and were less likely to have dived in the previous 12 months than those in the control group. Further analyses indicated that some variables were related to each other (e.g. age correlated with the total number of dives made; Spearman's correlation $r=0.47$, d.f. $=$ $86, P<0.001)$. In order to examine the effects of the different variables and their interactions on the dependent measures while taking these associations into account, and in order to test the main hypothesis that continued diving after NDCI would have a greater effect than either NDCI or diving alone, multiple regression analyses were performed. History of NDCI, age, number of dives within the last 12 months, total number of dives and interactions between these variables were entered into the analysis.

In addition, the 12 items from the symptom check-list were subjected to a factor analysis in order to reduce the number of variables. Three factors were found. Factor 1 consisted of hot or cold feelings, dizziness or vertigo, irritability, weakness or clumsiness and headaches. These are items associated with neurological damage. Factor 2 consisted of symptoms associated with head injuries: alcohol sensitivity, difficulty in concentrating and double vision. Factor 3 consisted of eyesight deterioration, ringing in the ears, poor appetite, hearing deterioration, primarily symptoms suggestive of damage to sensory organs. These factors are in accord with the literature on diving accidents.

Table 3 provides the results for the whole sample for GHQ scores and the three factors from the symptom check-list. Taking GHQ scores first, the only significant relationship was with the interaction between NDCI and the number of dives within the previous 12 months, accounting for $19 \%$ of the variance in GHQ. That is, subjects who continued to dive after NDCI were more likely to score highly on the GHQ and continuation of diving after NDCI accounted for more of the variance in psychological distress than did either NDCI or the number of recent dives considered separately, supporting the main prediction.
Table 3. Regression variables and standardized regression coefficients (SRC) for all divers

\begin{tabular}{llllll}
\hline $\begin{array}{l}\text { Outcome } \\
\text { measure }\end{array}$ & $\begin{array}{c}\text { Independent } \\
\text { variable }\end{array}$ & SRC & $\mathrm{F}$ & d.f. & Significance \\
\hline GHQ & Diving $\times \mathrm{NDCl}$ & 0.448 & 18.07 & 1 & $<0.001$ \\
Factor 1 & NDCl & 0.400 & 16.30 & 1 & $<0.001$ \\
& Dives this year & 0.432 & 19.01 & 1 & $<0.001$ \\
Factor 2 & Dives this year & 0.257 & 5.11 & 1 & $<0.05$ \\
Factor 3 & Total no. dives & 0.258 & 5.13 & 1 & $<0.05$ \\
\hline
\end{tabular}

Table 4. Regression variables and standardized regression coefficients (SRC) for the comparison group

\begin{tabular}{llrrrr}
\hline $\begin{array}{l}\text { Outcome } \\
\text { measure }\end{array}$ & $\begin{array}{l}\text { Independent } \\
\text { variable }\end{array}$ & SRC & F & d.f. Significance \\
\hline GHQ & No variables & & & & \\
Factor 1 & Dives this year & 0.842 & 21.22 & 1 & $<0.001$ \\
& No. dives $>30 \mathrm{~m}$ & -0.378 & 4.27 & 1 & $<0.05$ \\
Factor 2 & Dives this year & 0.416 & 8.56 & 1 & $<0.01$ \\
Factor 3 & Age & 0.342 & 5.42 & 1 & $<0.05$ \\
\hline
\end{tabular}

Table 3 also indicates that the significant variables associated with Factor 1 (neurological damage) were NDCI and number of dives in the previous 12 months. They accounted for $29 \%$ of the variance in Factor 1, but only $5 \%$ of the variance in both Factor 2 (head injury) and Factor 3 (sensory damage) could be accounted for by the number of dives this year and total number of dives respectively. These results indicate that the total number of dives, number of recent dives and NDCI have independent effects on perceived health symptoms.

In order to examine the effects of the independent variables on well-being in the absence of NDCI, a regression analysis was performed on the control group alone. The results of this analysis, shown in Table 4, indicated that none of the variables could be used to explain a significant amount of variation in GHQ scores. However, the number of dives within the previous 12 months and the number of dives over $30 \mathrm{~m}$ (negatively) accounted for $35 \%$ of the variance in Factor 1 scores, the number of dives within 12 months accounted for $15 \%$ of the variance in Factor 2, and age accounted for $10 \%$ of the variance in Factor 3 scores. These results suggest that the number of self-reported symptoms of ill-health increased as the total number of dives and number of dives in the previous 12 months increased.

\section{Discussion}

This study has provided some evidence that sports diving can be associated with impaired physical and psychological health in the longer term. Divers with past histories of NDCI were more likely to report some symptoms of neurological damage and to believe that diving had had deleterious effects on their health. They were also more likely to respond above the threshold for psychiatric difficulties and scored higher on the depression scale of the GHQ. 
Continuing diving after NDCI may be particularly important, since it was associated with increased psychiatric morbidity and reports of symptoms associated with neurological damage. These results suggest that NDCI can be associated with long-term disability and handicap in those who continue to dive after the accident. In subjects who had not undergone NDCI, the total number of dives and diving in the year preceding the survey were associated with reports of symptoms of neurological damage.

However, the study had a low response rate for both groups. It is possible that the responders in the NDCI group experienced more symptoms than did the non-responders, or that those in the control group who did not respond experienced more symptoms. These possibilities are made less likely by the finding that the two groups were similar on most demographic characteristics and that those differences which were found (in age and in diving activity at the time of the survey) would, in fact, tend to militate against the differences shown between the two groups.

Another possible criticism of this study is the reliance placed on self-report data. Episodes of NDCI may have sensitized divers to their health status, making them more aware of any health difficulties. While it can be argued that psychometric testing provides a more objective measure of impairment ${ }^{14}$, only self-reported data can identify handicaps and disabilities. A further difficulty in interpreting the results lies in establishing cause and effect. It may be that pre-existing neurological disorders in members of the NDCI group were causally related to their original accidents. Clearly, prospective studies, preferably using standard neurological tests as well as self-reports of health status, are required.

Despite these methodological difficulties, the results provide prima facie evidence that NDCI, diving after NDCI and diving itself can result in neurological and psychological changes. Although diving may have significant effects on only a small proportion of recreational divers, further research is merited, particularly for those who have a history of NDCI. This could result in a revision of medical advice on subsequent fitness to dive.

\section{References}

1 Rozsahegyi I. Late consequences of the neurological forms of decompression sickness. $\mathrm{Br}$ J Ind Med 1959; 16: 311-7.

2 Adkisson G, Macleod M, Hidgson M, Pearson R et al. Cerebral perfusion deficits in dysbaric illness. Lancet 1989; ii: 119-22.

3 Calder I, Palmer A, Hughes J, Bolt J, Buchanan J. Spinal cord degeneration associated with Type II decompression sickness: case report. Paraplegia 1989; 27: 51-7.

4 Edmonds $\mathrm{C}$, Broughton J. Intellectual deterioration with excessive diving (punch drunk divers). Undersea Biomed Res 1985; 12: 321-6.

5 Palmer A, Calder I, Hughes J. Spinal cord degeneration in divers. Lancet 1987; ii: 1365-6.

6 Palmer A, Calder I, Yates P. Cerebral vasculopathy in divers. Neuropathology and Applied Neurobiology (in press).
7 Peters B, Levin H, Kelly P. Neurologic and psychologic manifestations of decompression illness in divers. Neurology 1977; 27: 125-7.

8 Polkinghorne P, Cross M, Sehmi K, Minassian D, Bird A. Ocular fundus lesions in divers. Lancet 1988; ii: 1381-3.

9 Todnem K, Nyland H, Dick A, Lind O et al. Immediate neurological effects of diving to a depth of 360 metres. Acta Neurol Scand 1989; 80: 333-40.

10 World Health Organisation. International classification of impairments, disabilities and handicaps. Geneva, Switzerland: WHO, 1980.

11 Edmonds C, Hayward L. Intellectual impairment with diving: a review. Ninth International Symposium on Undersea and Hyperbaric Medical Society, Bethesda, Maryland, USA, 1987.

12 Dick A, Massey E. Neurologic presentation of decompression sickness and air embolism in sport divers. Neurology 1985; 35: 667-71.

13 Goldberg D, Hillier V. A scaled version of the General Health Questionnaire. Psychol Med 1979; 9: 139-45.

14 Holden R. Ocular fundus lesions in sports divers using safe diving practices. Br J Sports Med 1992; 26: 90-92.

\section{Appendix 1. RECOMPRESSION CHAMBERS}

Extensive facilities are available for helping with cases of dysbaric illness

Fifteen chambers under Ministry of Defence control operate in the UK. A further 14 chambers operate under civilian control. The addresses of these chambers are available from the British Sub-Aqua Club, 16 Upper Woburn Place, London WC1 0QW, UK.

Twenty-four hour specialist advice in managing diving accidents is available through the Royal Navy at Portsmouth (telephone 0705822351 (for general advice) or 0705818888 (FOR A LIFE THREATENING EMERGENCY ONLY), ext. 24875 during working hours, or ext. 22008 after hours). The Coastguard or Police can arrange for emergency transport if needed.

\section{Appendix 2. FIRST AID TREATMENT FOR DYSBARIC ILLNESS}

- $100 \%$ face mask oxygen

- Supine (head down and left lateral position if cerebral air embolism)

- Intravenous fluids (crystalloid or dextran - beware anaphylaxis)

- Intercostal chest drain if pneumothorax

- Catheterize if serious decompression sickness

- No analgesics without expert advice (especially those containing nitrogen such as Entonox)

- Intravenous heparin and steroids are controversial seek advice

- Urgently contact Portsmouth Royal Navy

(0705 822351 or 0705818888 ) for specialist advice

- Arrange transport to recompression chamber (low altitude if using helicopter). 